\title{
EVALUASI PORTAL BERITA ONLINE PADA ASPEK USABILITY MENGGUNAKAN HEURTISTIC EVALUATION DAN THINK ALOUD
}

\author{
Putu Tantri Fajarini $^{* 1}$, Ni Kadek Ayu Wirdiani ${ }^{2}$, I Putu Arya Dharmaadi ${ }^{3}$ \\ 1,2,3 Program Studi Teknologi Informasi, Fakultas Teknik, Universitas Udayana \\ Email: ${ }^{1}$ pututantrifajarini@gmail.com, ${ }^{2}$ ayuwirdiani@unud.ac.id, ${ }^{3}$ aryadharmaadi@unud.ac.id \\ "Penulis Korespondensi
}

(Naskah masuk: 27 Mei 2020, diterima untuk diterbitkan: 05 Oktober 2020)

\begin{abstract}
Abstrak
Portal berita online harus memenuhi beberapa aspek untuk bisa menjaga kualitas penggunaan dan informasi yang disediakan, salah satunya aspek usability. Aspek usability menentukan tingkat kebermanfaatan portal berita yang dinilai dari tingkat efektivitas, efisiensi, serta kepuasan dengan melakukan evaluasi usability. Penelitian ini bertujuan untuk melakukan evaluasi usability pada beberapa portal berita online di Indonesia untuk mendapatkan tingkat usability dari portal berita dan rekomendasi perbaikannya. Penelitian ini menggunakan 3 portal berita yang menyediakan berbagai macam berita yang terjadi baik itu berita lokal, nasional, hingga internasional secara aktual dan cepat. Evaluasi usability pada penelitian ini menggunakan 20 responden penelitian yang dipilih menggunakan simple random sampling dari pembaca dan staf portal berita yang dievaluasi. Pada penelitian ini, akan dilakukan evaluasi dengan mengkombinasikan teknik Heuristic Evaluation dan Think Aloud. Teknik Heuristic Evaluation digunakan untuk mengevaluasi antarmuka dengan menggunakan kuesioner heuristik dan Think Aloud digunakan untuk mengevaluasi penggunaan portal berdasarkan hasil verbalisasi masukan dari pengguna. Pada tahap pengumpulan data, setiap responden akan mengerjakan skenario tugas dengan memberikan masukan perbaikan atau kesulitan yang dirasakan. Responden selanjutnya akan melakukan pengisian kuesioner dari 10 aspek heuristik antarmuka portal. Hasil analisis data yang dilakukan menunjukkan bahwa penelitian telah berhasil mendefinisikan permasalahan dan rekomendasi perbaikan dari portal berita yang diievaluasi. Hasil analisis Heuristic Evaluation menunjukkan bahwa terdapat permasalahan pada 3 portal yang dievaluasi dengan tingkat minor yang prioritas perbaikannya rendah dengan rata-rata nilai severity ratings 2. Analisis Think Aloud menghasilkan 85 rekomendasi perbaikan dari 3 portal berita yang dievaluasi. Penelitian selanjutnya dapat melakukan evaluasi lanjutan dari implementasi rekomendasi perbaikan.
\end{abstract}

Kata kunci: evaluasi, usability, user experience, think aloud, heuristik

\section{ONLINE PORTAL EVALUATION ON USABILITY ASPECT USING HEURISTIC EVALUATION AND THINK ALOUD}

\begin{abstract}
Online news portals must meet several aspects to be able to maintain the quality of use and information provided, one of them is usability. The usability aspect determines the level of usefulness of the news portal which is assessed from the level of effectiveness, efficiency, and satisfaction by evaluating usability. This research aims to evaluate the usability of several online news portals in Indonesia to get the level of usability from news portals and recommendations for improvement. This research uses 3 news portals that provide a variety of news that occurs both locally, nationally, and internationally, in real time and quickly. Usability evaluation in this study used 20 research respondents who were selected using simple random sampling from readers and news portal staff who were evaluated. In this study, an evaluation will be conducted by combining Heuristic Evaluation and Think Aloud techniques. The Heuristic Evaluation technique is used to evaluate the interface using a heuristic questionnaire and Think Aloud is used to evaluate the use of the portal based on the results of verbalizing user input. At the data collection stage, each respondent will work on the task scenario by providing input on improvements or perceived difficulties. Respondents will then fill out questionnaires from 10 aspects of the portal interface heuristics. The results of data analysis carried out indicate that the research has succeeded in defining the problem and recommendations for improvement from the evaluated news portal. The results of the Heuristic Evaluation analysis showed that there were problems in 3 portals that were evaluated with a minor level with low priority improvement with an average severity ratings of 2. Think Aloud analysis yields 85 recommendations for
\end{abstract}


improvement from the 3 news portals evaluated. Future research can carry out further evaluations of the implementation of improvement recommendations.

Keywords: evaluation, usability, user experience, think aloud, heuristic.

\section{PENDAHULUAN}

Portal berita online menjadi salah satu media massa yang memiliki kekuatan penting dalam menyebarkan sebuah informasi. Permasalahan yang sering dikeluhkan pengguna adalah bagian antarmuka portal yang sulit dimengerti, dan fungsionalitas yang belum dapat digunakan dengan maksimal (Handiyani, 2016). Salah satu solusi yang dapat dijalankan untuk meningkatkan kualitas portal berita adalah dengan melakukan evaluasi (Farida, 2016). Evaluasi usability merupakan salah satu cara mengevaluasi sebuah produk atau sistem dari sisi antarmuka ataupun fungsionalitas dari sisi pengguna (Indriyani, 2017).

Evaluasi usability merupakan salah satu metode evaluasi sistem yang berfokus mengevaluasi seberapa baik pengguna dapat belajar dan menggunakan sistem, juga merujuk pada seberapa puas pengguna dengan prosesproses pada sistem (Farida, 2016). Metode evaluasi ini dikategorikan menjadi 3 yaitu inspection, testing dan inquiry (Gupta, 2015). Metode evaluasi usability memiliki banyak teknik, di antaranya Think Aloud, Cognitive Walkthrough, dan Heuristic Evaluation (Nielsen, 1993). Ketiga metode ini pernah dibandingkan dalam pengujian usability penggunaan smartphone yang menunjukkan metode Heuristic Evaluation menghasilkan nilai paling baik (Hendradewa, 2017). Studi kasus terkait evaluasi portal berita sudah pernah dilakukan menggunakan metode Heuristic Evaluation yang berhasil menemukan permasalahan aspek heuristik pada pada prinsip aesthetic and minimalist design (Ahsyar, 2019). Penelitian tersebut masih memiliki keterbatasan pada jumlah responden yang hanya 5 orang dan bukan pengguna portal langsung. Evaluasi dengan melibatkan pengguna memiliki kelebihan pada informasi mengenai bagaimana pengguna menggunakan sistem serta permasalahan yang dihadapi langsung oleh pengguna sistem. Metode testing adalah metode yang melibatkan pengguna pada proses evaluasinya (Gupta, 2015). Salah satu teknik dari metode testing yang berhasil menjabarkan kebutuhan pengguna adalah Think Aloud (Indriyani, 2017).

Think Aloud merupakan metode pengujian berbasis pengguna dengan melakukan verbalisasi secara kontinu terhadap apa yang dipikirkan saat menggunakan sistem (Astuti, 2014). Think Aloud dilakukan dengan mengamati pengguna ketika menggunakan sistem sehingga tidak membutuhkan seorang yang terlalu ahli dalam bidang usability (Ichsani, 2017). Think Aloud juga memiliki beberapa kelebihan, yaitu murah, kuat, fleksibel, meyakinkan, dan mudah digunakan (Nielsen, 1993).
Pada evaluasi pengalaman pengguna, dengan menggunakan 20-30 responden sudah dapat memberikan hasil yang baik dan stabil (Laugwitz, 2008). Pada studi kuantitatif, pengujian produk paling sedikit menggunakan 20 responden untuk mendapatkan angka statistik yang stabil (Nielsen, 2012). Sehingga peneliti di sini akan menggunakan 20 responden yang merupakan pengguna portal berita online yang akan dipecah menjadi responden mahir dan pemula (Indriyani, 2017).

Berdasarkan paparan diatas, pada penelitian ini akan dilakukan evaluasi usability portal berita online dengan mengkombinasikan metode Heuristic Evaluation (Ahsyar, 2019) dan Think Aloud. Hasil akhir penelitian ini diharapkan dapat memberikan manfaat teoretis terkait evaluasi usability dan manfaat praktis dalam memberikan rekomendasi perbaikan portal berita online yang dievaluasi.

Jurnal ini disusun dalam beberapa bagian, yaitu: Bagian 1 (Pendahuluan) menjelaskan latar belakang masalah terkait dengan evaluasi portal berita online; Bagian 2 (Metode Penelitian) berisi tahapan penelitian untuk melakukan evaluasi; Bagian 3 (Hasil dan Pembahasan) mencakup hasil evaluasi usability yang dilakukan dan implementasi perbaikan; dan akhirnya, Bagian 4 (Kesimpulan) terdiri dari beberapa poin penting yang disimpulkan.

\section{METODE PENELITIAN}

Metodelogi penelitian yang dilakukan dalam evaluasi portal berita ini ditunjukkan pada Gambar 1. Pada tahap persiapan akan dilakukan perumusan masalah yang diteliti, yaitu evaluasi portal berita dari aspek usability. Portal berita online yang akan dievaluasi adalah Tribunnews, Bali Post dan Jawa Pos. Studi literatur juga dilakukan pada tahap ini, dimana beberapa jurnal terkait evaluasi usability digunakan sebagai acuan penelitian ini. Persiapan data dan responden juga dilakukan pada tahap ini. Data diperlukan untuk mendukung keberhasilan dari evaluasi yang dihasilkan. Faktor yang perlu diperhatikan dalam melaksanakan penelitian ini yaitu sumber data, jenis data, metode pengumpulan data dan pengolahan data. Jenis data yang diperoleh dari proses evaluasi portal berita online ini berupa data kualitatif dan kuantitatif.

Pada penelitian ini akan digunakan 20 responden untuk mendapatkan angka statistik yang stabil (Laugwitz, 2008). Penentuan responden dilakukan dengan teknik simple random sampling (Sugiyono, 2017), dimana responden pada penelitian ini dipilih dari staf kantor Bali dari portal berita yang dievaluasi dan pembaca portal berita online. Responden tersebut kemudian dipecah menjadi 2 
kelompok yaitu mahir dan pemula, seperti ditunjukkan pada Tabel 1. Pengelompokkan ini bertujuan untuk mendapatkan perbandingan data efisiensi dan efektivitas produk (Yuliyana, 2019). Staf portal berita dimasukkan ke dalam responden mahir karena sudah mengerti struktur dari sebuah portal berita dengan pembaca portal dimasukkan ke dalam responden pemula.

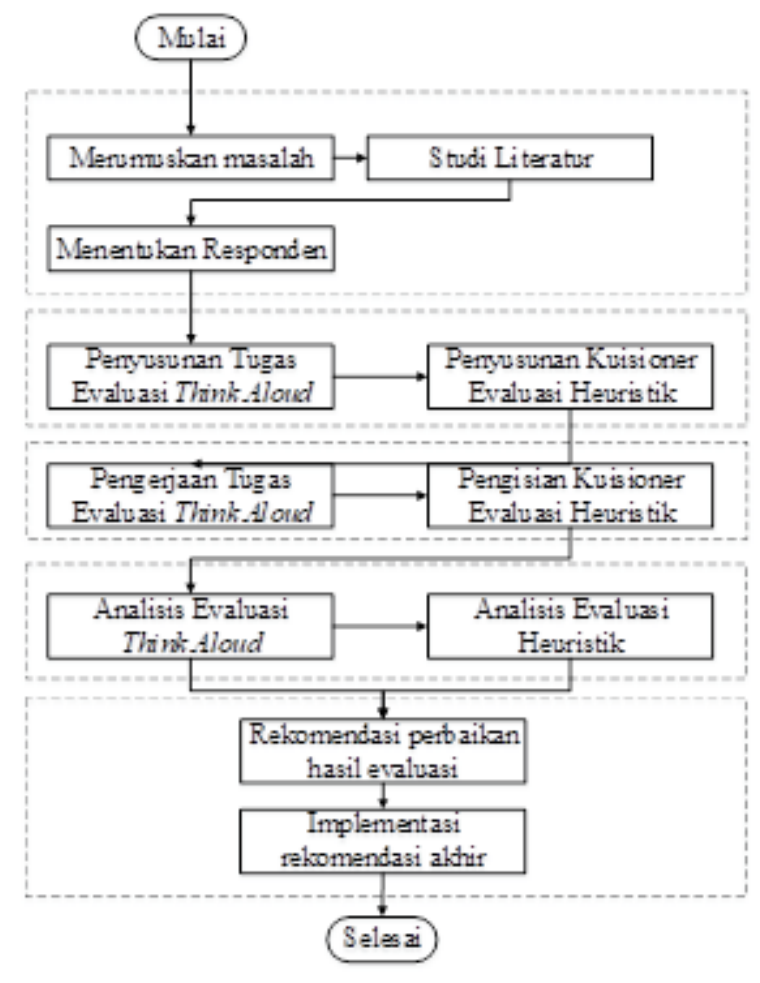

Gambar 1. Alur Penelitian

Tabel 1. Responden Penelitian

\begin{tabular}{clc}
\hline No & Responden & Jumlah Responden \\
\hline 1 & Mahir & 10 \\
2 & Pemula & 10 \\
\hline
\end{tabular}

Pengumpulan data pada penelitian ini dilakukan dengan menggunakan instrumen skenario tugas dan kuisioner heuristik. Evaluasi pada portal berita Tribunnews menggunakan 28 tugas, portal berita Bali Post menggunakan 25 tugas dan portal berita Jawa Pos menggunakan 26 tugas. Contoh tugas pada evaluasi ini dijabarkan pada Tabel 2. Penyusunan kuisioner heuristik dilakukan dengan menggunakan 10 prinsip heuristik yang ada.

\begin{tabular}{cc}
\multicolumn{2}{c}{ Tabel 2. Contoh Tugas } \\
\hline Kode & \multicolumn{1}{c}{ Tugas } \\
\hline \multirow{3}{*}{ TT2 } & $\begin{array}{l}\text { Saat ini Anda telah berada pada halaman utama } \\
\text { portal berita online. Silahkan menuju halaman } \\
\text { atau menu headline yang memuat berita utama } \\
\text { pada portal berita. }\end{array}$ \\
\hline
\end{tabular}

Data evaluasi Think Aloud dianalisis dengan melakukan perhitungan efisiensi, efektivitas dan rekapitulasi saran responden. Data rekapitulasi saran diperoleh dengan melakukan wawancara kepada responden saat melihat ulang hasil video rekaman.
Wawancara dilakukan untuk mengetahui pengalaman dan pendapat responden selama menggunakan portal berita. Pengolahan data dilakukan dengan megumpulkan hasil verbalisasi pemikiran responden. Verbalisasi tersebut meliputi saran ataupun kesulitan yang diutarakan responden beserta saran yang diberikan saat sesi pengujian selesai dilaksanakan (Sya'roni, 2018).

Pengukuran efektifitas dapat dihitung berdasarkan kegagalan tugas yang dikerjakan oleh setiap responden (Mifsud, 2015). Efektifitas dihitung dengan menetapkan angka biner " 1 " jika responden berhasil mengerjakan tugas dan "0" jika responden gagal (Wedayanti, 2019).

Gagal $=\frac{\text { jumlah tugas gagal }}{\text { jumlah total tugas }} \times 100 \%$

Pengolahan data efisiensi dilakukan dengan mengukur rata-rata waktu pengerjaan setiap tugas setiap responden. Waktu pengerjaan mulai dihitung setelah peneliti selesai membacakan tugas yang diberikan sampai responden telah selesai mengerjakan tugas. Hasil perhitungan akan menunjukkan tugas mana saja yang membutuhkan waktu paling lama untuk diselesaikan berdasarkan rata-rata waktu untuk mengerjakan setiap tugas dari seluruh responden yang ada (Handiwidjojo, 2016).

Data yang diperoleh dari kuisioner heuristik dianalisis menggunakan 10 prinsip Heuristic Evaluation. Prinsip Heuristic Evaluation memiliki nilai yang dihitung dengan persamaan (2). Selanjutnya untuk menghasilkan nilai severity rating dari tiap aspek heuristik digunakan persamaan (3).

$$
\begin{aligned}
& \sum \mathrm{Hx}=(0 * \mathrm{x})+(1 * \mathrm{x})+(2 * \mathrm{x})+(3 * \mathrm{x})+(4 * \mathrm{x}) \ldots \ldots \ldots \ldots \ldots \ldots \ldots \ldots \ldots \ldots \ldots \ldots \ldots \ldots \ldots \ldots \ldots \ldots \ldots \ldots \ldots \ldots \ldots \ldots \ldots \ldots \ldots
\end{aligned}
$$

Hasil analisis yang telah dilakukan kemudian akan direkapitulasi untuk mendapatkan kesimpulan akhir terkait hasil evaluasi portal berita online dan juga hasil rekomendasi perbaikan. Hasil rekomendasi perbaikan yang didapatkan kemudian dilakukan implementasi perbaikan ke dalam wireframe dengan menggunakan perangkat lunak bantuan untuk mendesain ulang perbaikannya.

\section{HASIL DAN PEMBAHASAN}

\subsection{Efektivitas}

Pengukuran efektifitas dihitung dari rata-rata nilai kegagalan pengerjaan task yang dikerjakan oleh 20 responden yang telah ditentukan dengan membagi responden menjadi dua kategori yaitu, kategori mahir dan pemula. Hasil pengolahan data efektifitas ditampilkan pada Tabel 3 .

Hasil data efektivitas menunjukkan mayoritas tugas tidak berhasil dikerjakan. Analisis kegagalan 
dilakukan dengan melakukan pengamatan ulang terhadap video pengerjaan tugas responden. Tabel 4 merupakan contoh penyebab kegagalan pengerjaan tugas yang berhasil dianalaisis.

\begin{tabular}{cccc}
\multicolumn{4}{c}{ Tabel 3. Hasil Data Efektivitas } \\
\hline \multirow{2}{*}{ Responden } & \multicolumn{3}{c}{ Portal Berita } \\
\cline { 2 - 4 } & Tribunnews & Bali Post & Jawa Pos \\
\hline Mahir & $48,21 \%$ & $52,40 \%$ & $47.31 \%$ \\
Pemula & $48,21 \%$ & $58,80 \%$ & $52,69 \%$ \\
\hline
\end{tabular}

Tabel 4. Penyebab Kegagalan Pengerjaan Tugas

\begin{tabular}{ccl}
\hline $\begin{array}{c}\text { Kode } \\
\text { Tugas }\end{array}$ & $\begin{array}{c}\text { Responden } \\
\text { Gagal }\end{array}$ & \multicolumn{1}{c}{ Penyebab Kegagalan } \\
\hline \multirow{3}{*}{ TT2 } & 6 & $\begin{array}{l}\text { Responden sulit menemukan headline, } \\
\text { seharusnya perlu di kategorikan mana } \\
\text { yang merupakan headline agar } \\
\text { pengguna tidak keliru dan } \\
\text { kebingungan. Ukuran font juga } \\
\text { seharusnya lebih besar. }\end{array}$ \\
\hline
\end{tabular}

\subsection{Efisiensi}

Efisiensi diukur dengan menghitung rata-rata waktu responden dalam mengerjakan tugas yang diberikan dalam satuan detik, seperti ditunjukkan pada Tabel 5 .

\begin{tabular}{cccc}
\multicolumn{4}{c}{ Tabel 5. Hasil Data Efisiensi } \\
\cline { 2 - 4 } Responden & \multicolumn{3}{c}{ Waktu Pengerjaan } \\
\cline { 2 - 4 } & Tribunnews & Bali Post & Jawa Pos \\
\hline Mahir & 13.04 & 25.20 & 22.20 \\
Pemula & 13.50 & 27.17 & 23.17 \\
\hline
\end{tabular}

Hasil data efisiensi juga dilakukan analisis, dimana diamati penyebab lamanya responden mengerjakan tugas. Perbedaan waktu pengerjaan tugas disebabkan oleh responden kategori pemula lebih banyak mencoba mencari-cari fitur atau konten yang ditugaskan, karena kebingungan dalam menyelesaikan tugas yang diberikan.

\subsection{Think Aloud}

Pada Think Aloud, akan dicatat setiap masukan dan kesulitan yang dikemukakan oleh responden. Saran yang dikemukakan oleh masing-masing responden akan diringkas menjadi rekomendasi akhir perbaikan. Pada Tabel 6 dijabarkan beberapa saran yang dikemukakan oleh responden pada saat menjalankan setiap task yang diberikan.

\begin{tabular}{clc} 
& Tabel 6. Saran Perbaikan Responden & \\
\hline Kode & \multicolumn{1}{c}{ Saran Responden } & Portal \\
\hline SRM2 & $\begin{array}{l}\text { Penempatan "Breaking News" pada } \\
\text { portal diurutkan setelah berita utama }\end{array}$ & Tribunnews \\
SRM1 & $\begin{array}{l}\text { Penempatan berita utama pada portal } \\
\text { Bali Post seharusnya dibagian awal. }\end{array}$ & Bali Post \\
SRP2 & $\begin{array}{l}\text { Halaman "Editor Pick" bisa } \\
\text { menggunakan Bahasa Indonesia. }\end{array}$ & Jawa Pos \\
\hline
\end{tabular}

\subsection{Heuristic Evaluation}

Hasil data Heuristic Evaluation diperoleh berdasarkan hasil penilaian responden dari kuisioner yang telah dibagikan setelah melaksanakan tugastugas pada evaluasi Think Aloud. Hasil penilaian kuisioner yang diberikan oleh responden kategori mahir (M) dan pemula (P) akan ditampilkan pada Gambar 2.

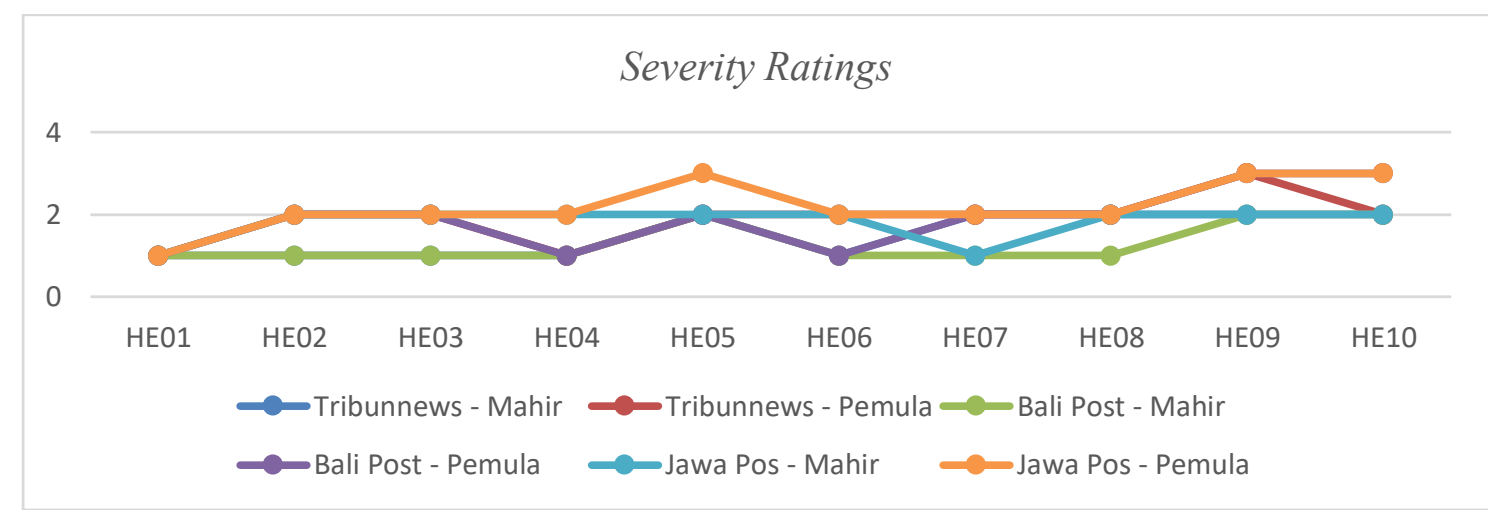

Gambar 2. Grafik Rekapitulasi Severity Ratings

Permasalahan usability pada portal berita ini dinilai menggunakan severity ratings yang didefinisikan oleh Nielsen (Nielsen. 1993). Masalah usability yang ada pada portal berita ditunjukkan dengan skor severity ratings 3, 2 dan 1 . Nilai severity ratings 3 artinya bahwa terdapat masalah usability mayor, perbaikan menjadi prioritas tinggi. Nilai severity ratings 2 artinya bahwa terdapat masalah usability minor, perbaikan aspek ini menjadi prioritas rendah. Nilai severity ratings 1 artinya bahwa terdapat masalah estetika portal yang dapat diperbaiki apabila disediakan waktu.

\subsection{Wireframe Rekomendasi Perbaikan}

Berdasarkan rekomendasi perbaikan yang dihasilkan, Gambar 3 merupakan hasil implementasi wireframe dari rekomendasi perbaikan pada portal berita Tribunnews yang ada pada Tabel 6. Perbaikan dilakukan dengan melakukan penambahan menu "Breaking News" yang ukuran hurufnya dibuat lebih besar agar pengguna lebih mudah menemukannya (Purwaningsih, 2015). Penambahan "Breaking News" juga diperbaiki agar lebih memudahkan pengguna dalam melakukan pencarian berita. 


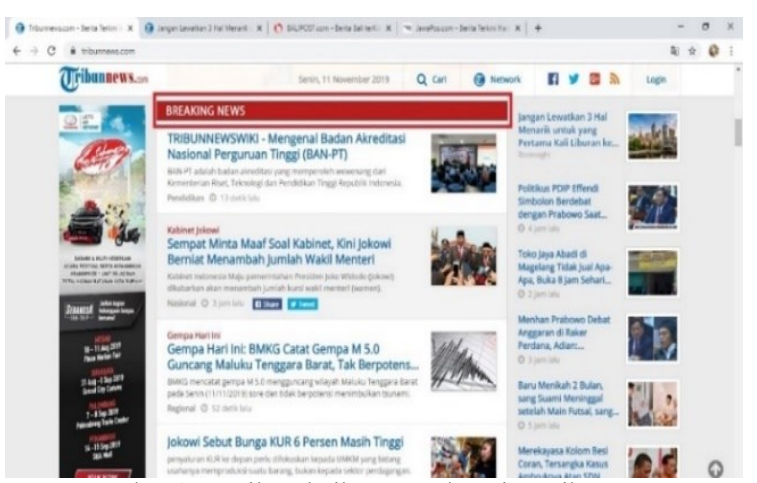

Gambar 3. Hasil Perbaikan Portal Berita Tribunnews

Gambar 4 merupakan hasil rekomendasi perbaikan pada portal berita Bali Post berupa perubahan pada nama judul "Berita Terkini" yang lebih diperjelas sesuai rekomendasi pada Tabel 6.

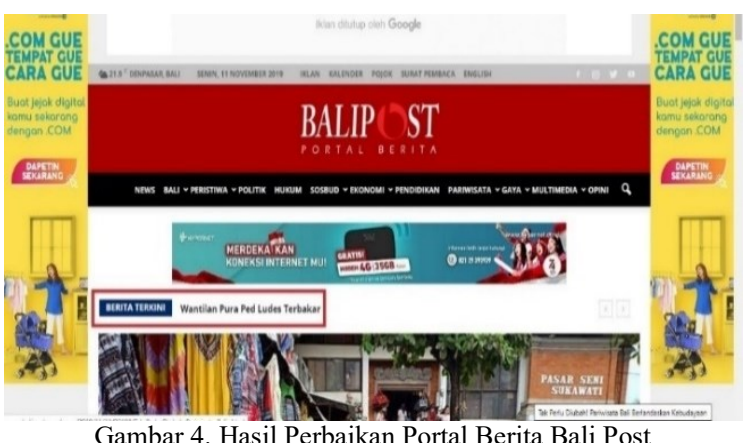

Gambar 5 merupakan hasil perbaikan dari portal berita Jawa Pos pada tampilan judul pilihan tim editor portal berita Jawa Pos. Hasil rekomendasi berupa perubahan dalam penamaan judul "Editor's Pick" menjadi "Pilihan Tim Editor" agar pengguna dengan mudah mencari berita yang diinginkan Tabel 6 .

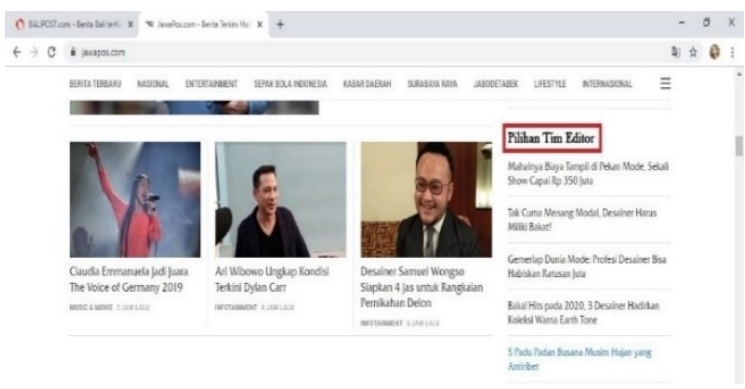

Gambar 5. Hasil Perbaikan Portal Berita Jawa Pos

\section{KESIMPULAN}

Hasil analisis Heuristic Evaluation menghasilkan nilai rata-rata severity ratings seluruh aspek baik dari responden kategori mahir maupun pemula sebesar 2 pada Tribunnews, sebesar 2 pada Bali Post dan sebesar 2 pada Jawa Pos. Nilai severity ratings 2 menunjukkan bahwa terdapat masalah dengan tingkat minor dengan perbaikan menjadi prioritas rendah.
Hasil analisis efektivitas dan efisiensi, menunjukkan bahwa portal berita Bali Post merupakan portal berita dengan tingkat keberhasilan pengerjaan tugas terkecil dan waktu pengerjaan tugasnya yang lama. Efektivitas portal berita Bali Post pada responden pemula persentasenya $41.20 \%$ sedang pada responden mahir $47,60 \%$. Hasil analisis efisiensi pada portal Bali Post mendapatkan waktu pengerjaan rata-rata 27.17 detik untuk responden pemula dan 25.20 untuk responden mahir. Hasil akhir analisis Think Aloud menghasilkan 28 rekomendasi perbaikan pada Tribunnews, 26 rekomendasi perbaikan pada Bali Post dan 31 perbaikan rekomendasi perbaikan pada Jawa Pos. Penelitian selanjutnya dapat melakukan evaluasi lanjutan dari hasil implementasi yang dihasilkan, seperti evaluasi TAM dan UTAUT untuk mengukur kesuksesan penerapan sistem informasi berdasarkan keinginan atau masukan pengguna dalam menggunakan hasil implementasi perbaikan (Hamrul, 2013).

\section{UCAPAN TERIMA KASIH}

Penulis mengucapkan banyak terima kasih kepada Tuhan Yang Maha Esa, karena atas rahmatNya penelitian ini dapat diselesaikan dengan lancar. Terima kasih juga penulis ucapkan kepada dosen pembimbing tugas akhir yang membimbing dan memberikan arahan dari awal penelitian ini dilakukan.

\section{DAFTAR PUSTAKA}

ASTUTI, I., KUSUMA, W. A. \& ARDIANSYAH, F., 2014. Analisis Usability Homepage Situs Web Perpustakaan Nasional RI Menggunakan Metode Think Aloud. Jurnal Pustakawan Indonesia, Vol. 15, No. 1-2, pp. $39-47$.

AHSYAR, T. K., \& AFANI, D., 2019. Evaluasi Usability Website Berita Online Menggunakan Metode Heuristic Evaluation. Jurnal Ilmiah Rekayasa dan Manajemen Sistem Informasi, Vol. 5, No. 1, pp. 34-41.

FARIDA, L. D., 2016. Pengukuran User Experience Dengan Pendekatan Usability (Studi Kasus:Website Pariwisata Di Asia Tenggara). Seminar Nasional Teknologi Informasi dan Multimedia, pp. 55 - 60 .

GUPTA, S., 2015. A Comparative study of Usability Evaluation Methods. International Journal of Computer Trends and Technology (IJCTT), Vol. 22, No. 3, pp. 103 - 106.

HAMRUL, H., SOEDIJONO, B., \& AMBOROWATI, A., 2013. Analisis Perbandingan Metode TAM dan UTAUT Dalam Mengukur Kesuksesan Penerapan Sistem Informasi Akademik (Studi Kasus Penerapan Sistem Informasi Stmik 
Dipanegara Makassar). Seminar Nasional Informatika 2013, pp. 140 - 146.

HANDIWIDJOJO, W., \& ERNAWATI, L., 2016. Pengukuran Tingkat Ketergunaan (Usability) Sistem Informasi Keuangan Studi Kasus: Duta Wacana Internal Transaction (Duwit). JUISI, Vol. 02, No. 01, pp. $49-55$.

HANDIYANI, P., \& HERMAWAN, A., 2016. Kredibilitas Portal Berita Online Dalam Pemberitaan Peristiwa Bom Sarinah Tahun 2016 (Analisis Isi Portal Berita Detik.com dan Kompas.com Periode 14 Januari- 14 Februari 2016). Jurnal Komunikasi, Volume 12, Nomor 1, pp. 51 - 68.

HENDRADEWA, A. P., 2017. Perbandingan Metode Evaluasi Usability (Studi Kasus : Penggunaan Perangkat Smartphone. Teknoin, Vol. 23, No. 1, pp. $09-18$.

ICHSANI, Y., 2017. Usability Performance Evaluation of Information System with Concurrent Think-Aloud Method as User Acceptance Testing: A Literature Review. International Conference on Science and Technology, pp.116 - 121 .

INDRIYANI, R., DANTES, G. R., DAN ARYANTO, K. Y. E., 2017. Analisis Kebermanfaatan Website Sekolah Tinggi Pariwisata (STIPAR) Triatma Jaya Menggunakan Metode Usability Testing. International Journal of Natural Science and Engineering, Vol.1, No. 2, pp. 56-64.

JASPERS, M. W. M., 2009. A comparison of usability methods for testing interactive health technologies: Methodological aspects and empirical evidence. International Journal of Medical Informatics, 78(5), 340353.

https://doi.org/10.1016/j.ijmedinf.2008.10.0 02

LAUGWITZ, B., HELD, T. \& SCHREPP, M., 2008. Construction and Evaluation of a User Experience Questionnaire. HCI and Usability for Education and Work. Symposium of the Austrian HCI and Usability Engineering Group, pp. 63-76.

MIFSUD, J., 2015. Usability Metrics - A Guide to Quantify the Usability of Any System, [online] Tersedia di $<$ https://usabilitygeek.com/usability metrics-a-guide-to-quantify-systemusability/ > [Diakses 2 Maret 2020]

NIELSEN, J., 1993. Usability Engineering. AP Professional : California.

NIELSEN, J., 2012. Thinking Aloud: The \#1 Usability Tool, [online] Tersedia di : $<$ https://www.nngroup.com/articles/thinkin g-aloud-the-1-usability-tool/> [Diakses 5 Maret 2020].

PARAMITHA, I., INDRAWAN, G. DAN DANTES, G. R., 2018. The Evaluation of Web Based Academic Progress Information System Using Heuristic Evaluation and User Experience Questionnaire (UEQ). International Conference on Informatics and Computing, $\quad$ pp. $\quad 1 \quad-\quad 6$. https://doi.org/10.1109/IAC.2018.8780430.

PAZ, F., PAZ, F. A., VILLANUEVA, D., \& POWSANG, J. A., 2015. Heuristic Evaluation as a Complement to Usability Testing: A Case Study in Web Domain. In 2015 12th International Conference on Information Technology - New Generations, pp. 546551. https://doi.org/10.1109/ITNG.2015.92

PURWANINGSIH, R., \& YENIFI, I., 2015. Usability Assessment of International Office Website Of Diponegoro University With Scenario - Based Usability Evaluation Method And WAMMI Method. ComTech, Vol. 6, No. 3, pp. 329-342.

SUGIYONO, 2017. Statistika Untuk Penelitian (Cetakan $\mathrm{Ke}-28)$. Alfabeta : Bandung.

SYA'RONI, M. I., KHARISMA, A. P. \& AMALIA, F., 2018. Perbandingan Hasil Metode Evaluasi Usability Antara Heuristic Evaluation dengan Think Aloud pada Kasus Web FILKOM APPS untuk Mahasiswa. Jurnal Pengembangan Teknologi Informasi dan Ilmu Komputer, Vol. 2, No. 2, pp. $674-$ 678.

WEDAYANTI, A., WIRDIANI, A., \& PURNAWAN, A. 2019. Evaluasi Aspek Usability pada Aplikasi Simalu Menggunakan Metode Usability Testing. Jurnal Ilmiah Merpati, Vol. 7, No. 2, pp. 113 $-124$.

YULIYANA, T., ARTHANA, I. \& AGUSTINI, K., 2019. Usability Testing pada Aplikasi POTWIS. Jurnal Sains dan Teknologi, Vol. 8, No.1, pp. $12-22$. 